\title{
Capacetes Azuis brasileiros no Haiti: instrumento de smart power para a política externa do Brasil?
}

\author{
Brazilian Blue Helmets in Haiti: an instrument \\ of Smart Power for Brazil's Foreign Policy?
}

Rev. Bras. Est. Def. v. 6, nº 1, jan./jun. 2019, p. 79-108

DOI: 10.26792/RBED.v6n1.2019.75102

ISSN 2358-3932

\section{RAFAEL FARIAS \\ RODRIGO PERLA MARTINS}

\section{INTRODUÇÃO}

A Minustah significou um novo tipo de inserção internacional para o Brasil: maior contingente militar presente e chefia do componente militar da missão. De acordo com Kenkel (2011), a experiência vivenciada no Haiti ensejou a construção de um modelo que tem ido muito mais longe que o processo político na transformação, em ações concretas, dos preceitos estabelecidos nos documentos da política declaratória brasileira e na sua longa tradição de política externa. O modelo haitiano, comumente associado ao Brazilian Way of Peacekeeping, estabelece uma sinergia entre a propensão brasileira para a negociação e a resolução pacífica de conflitos com o foco

\footnotetext{
Rafael Farias - Graduado em Ciências Militares pela Academia Militar das Agulhas Negras (2000), com a formação de oficial de carreira da arma de engenharia. Tem experiência nas áreas de Logística em Operações de Paz e Desminagem Humanitária. Foi instrutor de desminagem humanitária do Centro de Aperfeiçoamento em Ações de Desminagem e Despoluição (CPADD) - Benin e de logística da Organização das Nações Unidas (ONU) no Centro Internacional de Defesa da Noruega (NODEFIC). Foi o responsável pela coordenação e condução do estágio de logística e reembolso do Centro Conjunto de Operações de Paz do Brasil (CCOPAB). É mestre em Ciências Militares pela Escola de Comando e Estado-Maior do Exército (ECEME), na linha de pesquisa gestão da defesa. rafaelfarias.2672@gmail.com.

Rodrigo Perla Martins - Doutor em História pela PUC-RS (2011). Mestre em Ciência Política pela UFRGS (1999). Possui curso de especialização em Processos de Integração Internacional pela Leiden University (The Netherlands/Holanda - 1999). Graduação em História pela UFRGS — Licenciatura (1995) e Bacharelado (1996). Atualmente é professor-adjunto do curso de História na Universidade Feevale em Novo Hamburgo - RS, Vice-coordenador do GT História das Relações Internacionais junto à ANPUH-Brasil (Associação Nacional de História) e coordenador do GT de História das Relações Internacionais - seção regional - junto à ANPUH-RS. Participante do Projeto de extensão "O mundo em Novo Hamburgo: refugiados e migrantes, uma questão de direitos humanos" - vinculado ao Programa de Extensão Educação e Cultura dos Direitos Humanos da Universidade Feevale. rodrigomartins@feevale.br.
} 
tradicional do país, tanto interno como na política externa, sobre o desenvolvimento econômico sustentável (Kenkel 2011).

O trabalho destina-se a analisar se a presença do Brasil na Minustah pode ser entendida como instrumento de Smart Power para a sua política externa. Apresentam-se inicialmente pressupostos teóricos acerca de Hard, Soft e Smart Power, de forma a delimitar o escopo da pesquisa, sucedidos de uma discussão sobre os motivos que conduzem uma nação a participar de operações de manutenção da paz, à luz da Teoria das Relações Internacionais. Em seguida, discorre-se sobre a inserção das operações de manutenção de paz na política externa brasileira. Nas duas seções subsequentes, merecem destaque a abordagem do Hard, Soft e Smart Power evidenciado na missão. Inicialmente, apresentam-se as expressões militar e econômica, essa conduzida mediante uma pesquisa quantitativa e qualitativa das empresas presentes na ilha caribenha, para, então, analisar a combinação do Poder duro e do Poder brando pelos capacetes azuis. Na conclusão, realiza-se uma apreciação acerca da combinação inteligente entre o Hard e o Soft Power a partir da experiência do contingente brasileiro no Haiti.

\section{CONCEITOS DE HARD, SOFT E SMART POWER}

Carr (2001) ressaltou que o poder militar, que viria a constituir um dos elementos do hard power, exerceu grande protagonismo ao longo dos séculos. Para Carr (2001), a guerra desempenhava um fator dominante na política internacional, fazendo com que o poderio militar se tornasse um padrão aceito no âmbito dos valores políticos. Consoante com essa interpretação, o emprego de tropas no exterior em Operações de Manutenção da $\mathrm{Paz}(\mathrm{OMP})$, por vezes mediante a utilização da expressão do poder militar, poderia contribuir para o aumento do poder de uma nação, em uma acepção realista da Teoria das Relações Internacionais.

Ainda com relação a este preâmbulo do hard power, Morgenhtau (2003), define o "poder" como a força de um homem sobre as mentes e as ações de outros homens. O autor ressalta a Capacidade industrial e o Grau de Preparação Militar (Tecnologia, Liderança, Quantidade e qualidade das FA) como um os elementos do poder nacional. ${ }^{1}$

A extensão territorial, o poder militar e o poder econômico são três fatores que devem ser considerados para qualificar um país como potência e compreender sua posição na hierarquia entre Estados (Morgenthau 2003; Bandeira 2009). Estes são os fatores que permitem a um Estado atuar independentemente e influir sobre outros Estados e, portanto, determinar em que condições ele se expressa como potência regional internacional. 
Bandeira (2009) salienta que um Estado, dispondo de potencial econômico, força militar e extensão territorial pode tornar-se hegemônico, o líder e o guia de um sistema de alianças e acordos de variado alcance. Ademais, faz-se necessário que o Estado tenha capacidade de exercer pressão diplomática, o que implica capacidade para obter parte do que poderia ser o resultado de uma guerra vitoriosa, sem a necessidade de, efetivamente, entrar em combate (Bandeira 2009, 77).

A interação entre meios dissuasórios de uma nação e a sua capacidade de fazer pressão diplomática mereceu especial atenção de Keohane e Nye (2012). Consoante com os autores, o término da guerra fria permitiu a emergência de novos atores, em uma conjuntura mundial em que os países estão conectados por múltiplas relações sociais e políticas, e passam a coexistir novas expressões do poder. A partir do estudo de Keohane e Nye, foram sistematizados os conceitos de hard power (poder duro) e de soft power (poder brando).

O hard power refere-se ao uso de meios militares e econômicos para coagir ou influenciar o comportamento e interesses de outra entidade política (Nye 2011). O poder duro refere-se a táticas de coerção, tanto de cunho militar, como o uso ou ameaça da força, quanto econômico, como pressão e sanções econômicas. O hard power, na tradição realista, tem sido a medida por excelência de poder nacional. Pode ser quantificado por critérios tais quais os ativos militares, inclusive a disposição de capacidades industriais e tecnológicas de defesa, e o Produto Interno Bruto (PIB) (Nye 2011).

O soft power remete ao exercício do poder por meio de influência, persuasão e capacidade de atração, repousando sobre três recursos fundamentais: cultura, valores políticos e política exterior (Nye 2011). Ainda de acordo com o autor, os recursos econômicos são uma potencial fonte geradora de poder brando. Igualmente, recursos de poder militar podem contribuir para a formação de poder brando. Segundo esta acepção, recursos tradicionais de hard power podem contribuir para aumentar a atratividade do "modelo" de um país, sempre e quando o Estado encontrar legitimidade entre seus pares. Ao elevar seu poderio militar e econômico, um Estado terá maior poder de influência e de atração.

Nye (2004), por meio do termo "poder inteligente", instituiu a inter-relação e a dependência mútua entre os dois conceitos. O smart power diz respeito à combinação do poder duro da coerção e da sanção com o poder brando da persuasão e atração. Nye esclarece que o smart power refere-se à habilidade de aplicar as duas formas de poder em estratégias coerentes e eficazes e em diferentes contextos. O smart power não é nem duro e nem brando, é uma engenhosa combinação de ambos, por meio da qual ressal- 
ta-se a necessidade de FA fortes, mas também investe pesadamente em alianças, parcerias e instituições em todos os níveis.

No que concerne à dimensão brasileira do smart power, escopo deste trabalho, questiona-se por que o país exerceria o soft power em sua política externa. Murray e McCoy (2010, 175), ao analisarem características em comum de países como Austrália, Canadá e Brasil, consideram que aspectos de ordem econômica e militar as tornam potências médias. Valença e Carvalho (2014) salientam que o Brasil é um global player, mas não uma potência global, com limitadas capacidades de hard power para exercer suas aspirações internacionais, o que leva Chatin (2016) a considerar que o poder brando seria mais uma necessidade do que uma opção para a sua política externa.

Chatin (2016) também defende que o país não é uma potência emergente militar e que não manifestara um real interesse em se tornar uma potência militar. Para a autora, as limitadas capacidades militares do Brasil — único dentre os BRICS que não é uma potência nuclear — restringem as condições de conduzir a política externa por meio de hard power. Na ausência de meios mais robustos, as principais estratégias do governo brasileiro têm sido diretamente ligadas ao soft power (Valença and Carvalho 2014).

Ainda de acordo com Chatin (2016), um país pacífico, conciliatório, multilateral, de tradição legalista e a sua dimensão socioeconômica tornaram o Brasil uma nação emergente que alcançou projeção internacional por meio do soft power. Chatin (2016) destaca que Valença e Carvalho (2014), por sua vez, salientam que a política externa do país tem sido majoritariamente marcada pela adoção de componentes não-materiais de poder e por estratégias de persuasão e construção de consenso.

Nasser (2012), ao analisar a estratégia diplomática brasileira para a participação em operações de paz, salienta que influência é poder, aspecto presente na política externa desde a gestão de Barão do Rio Branco como chanceler do país. Para Nasser (2012), a solidariedade prestada às demais nações torna-se um instrumento de projeção de poder. Nesses termos, a atuação de capacetes azuis brasileiros poderia ser entendida como uma manifestação do poder de influência (soft power) e, ao mesmo tempo, de hard power, haja vista a utilização de um recurso tipicamente militar em proveito da paz.

\section{MOTIVAÇÕES PARA A PARTICIPAÇÃO EM MISSÕES DE PAZ}

Para Godofredo Júnior (2005), a política externa brasileira alterna posições realistas e idealistas, particularmente no que concerne ao posicionamento do país diante de fóruns e de organismos internacionais, assim como na solução de controvérsias com outras nações. Consoante com esta 
interpretação, os interesses em participar de missões de paz também poderiam alternar posições realistas e idealistas, em uma acepção que, para o Brasil, insere-se na perspectiva da tradição grociana das relações internacionais.

Kai Kenkel, ao analisar os interesses do Brasil em missões sob a égide da Organização das Nações Unidas (ONU), apresenta o que motiva as chamadas potências médias para participar de tais operações (Kenkel 2011). Conforme o autor, existem motivações que podem ser idealistas — os Estados integram OMP sob a égide da ONU por uma obrigação de proteger a paz internacional e para preservar normas e valores internacionais - e, ao mesmo tempo, realistas - a participação dos Estados em OMP ocorre para proteger e preservar os interesses nacionais (Kenkel 2011).

Referente à abordagem idealista, Aguilar (2015) ressalta a importância do Brasil em participar dos esforços de desenvolver e promover justiça social no Haiti e nos demais países envolvidos em processos violentos, convergindo para o que o pesquisador Ricardo Seitenfus conceitua como “diplomacia solidária”. Esse tipo de diplomacia refere-se à concepção e à aplicação da ação coletiva "feita por terceiros Estados intervenientes num conflito interno ou internacional, desprovidos de motivações decorrentes de seu interesse nacional e movidos unicamente por um dever de consciência” (Seitenfus 2006 apud Aguilar 2015). Amorim (2011) salienta que, no caso do Haiti, ao princípio da não-intervenção (Brasil 1988), agregou-se o da "não-indiferença" (Pecequilo 2014), que implica a prestação de solidariedade a países atravessando situações difíceis, sempre por meio de canais legítimos. Consoante com esses autores, o protagonismo brasileiro na Minustah está ligado à “diplomacia solidária”, em uma acepção idealista da participação em OMP.

No que se refere à abordagem realista, Krishnasamy e Weigold (2003) concluíram que o aumento expressivo do envio de contingentes da Índia para OMP proporcionou a este país oportunidades para não apenas fortalecer e aumentar ainda mais sua presença dentro da ONU, mas também para ser considerado um candidato mais favorável a um assento permanente no Conselho de Segurança das Nações Unidas (CSNU). No que concerne às razões que conduziram o Brasil ao Haiti, Kenkel (2011) assegura que a utilidade das operações de paz como meio para atingir maior influência internacional deriva fortemente da disponibilidade expressa para assumir a responsabilidade global, sinalizada pela participação nessas missões. Dessa forma, a participação em operações de paz poderia ser entendida como parte de um esforço voltado para os benefícios a serem obtidos em termos de política externa e, sobretudo, de projeção de poder no concerto das nações. 


\section{O BRASIL E A MINUSTAH}

O Brasil participa de missões desde os anos de 1930 e, no âmbito da ONU, desde 1957 (Fontoura 2005). Estas missões concentraram-se, majoritariamente, nas Operações de Manutenção da Paz (OMP). Após um período de retraimento — de 1967 até 1989 não foram desdobradas tropas para o exterior —, o país retoma, na década de 1990, sua participação, enviando grandes efetivos brasileiros para missões de paz, vicejando uma política de Estado que perpassou as diferentes presidências. Em 1993, foi enviada uma companhia de infantaria com 170 homens para Moçambique ${ }^{2}$ (Aguilar 2012) e, dois anos depois, chegou a desdobrar 1.300 homens em Angola, ${ }^{3}$ a maior força militar fora do país desde a Segunda Guerra Mundial (Garcia 2004, 254).

Em 2004, o Brasil passou a integrar a Missão da Organização das Nações Unidas no Haiti (Minustah), tendo enviado mais de 32 mil homens e mulheres para o país centro-americano (Hamann 2016). O cerne do interesse nacional gira em torno de três eixos prioritários: (1) Haiti; (2) países lusófonos (Angola, Moçambique e Timor Leste e, em menor escala, Guiné Bissau); e (3) Líbano (Hamann 2016). Como primeira prioridade, a Minustah ensejou uma nova perspectiva para o emprego de capacetes azuis do Brasil.

O envio de capacetes azuis brasileiros para OMP também pode ser analisado a partir do paradigma logístico de inserção internacional (Cervo e Bueno 2015). O ensaio de Estado logístico recuperou estratégias de desenvolvimento e conferiu à política exterior funções assertivas: $i$ ) o reforço da capacidade empresarial do país; ii) a aplicação da ciência e da tecnologia assimiladas; iii) a abertura dos mercados do Norte em contrapartida ao nacional; e iv) uma política de defesa nacional (Cervo e Bueno 2015, 495).

A importância da participação das Forças Armadas (FA) em OMP foi ressaltada pela Política Nacional de Defesa (PND), de forma a "ampliar a projeção do País no concerto mundial e reafirmar seu compromisso com a defesa da paz e com a cooperação entre os povos" (Brasil 2012a, 33). Igualmente, a Estratégia Nacional de Defesa (END) reforça a necessidade de "Preparar as Forças Armadas para desempenharem responsabilidades crescentes em operações internacionais de apoio à política exterior do Brasil” (Brasil 2012b, 59).

Hoelscher e Norheim-Martinsenb (2014) salientam as tentativas de alavancar o poder econômico emergente do Brasil nos anos $2000 \mathrm{em}$ um novo papel político no cenário global. Igualmente, Kenkel (2013) ressalta que a espiral de crescimento do PIB nesta década permitiu que os policy makers transformassem a nova prosperidade encontrada em maior política 
global e em estratégia de influência, e as OMP tornam-se peça-chave nesse processo.

O Brasil vinha tendo uma grande projeção internacional e a missão significaria uma oportunidade única para o país (Amorim 2011). Antes do estabelecimento do mandato para a missão por parte da ONU, as ações no Haiti haviam sido quase sempre comandadas por uma grande potência, normalmente os Estados Unidos. Nunca um país da América Latina ou, mais especificamente, um país da América do Sul havia estado à frente (Amorim 2011). Nesse sentido, a liderança brasileira na Minustah, em um momento único de sua política externa $\left(F_{\text {ortuna }}^{4}\right)$, passou a ser marcado pela presença do maior contingente e pela chefia do componente militar da missão (Virtì ${ }^{5}$ ), mostrando-se como uma Raison d'Etat para o Brasil.

No que concerne ao interesse nacional, sua essência, assim como a importância da autonomia, são base para o desenvolvimento da nação, tanto em sua dimensão externa como interna (Visentini 2013). Consoante com esta assertiva, a liderança do componente militar da Minustah, assim como o maior efetivo da missão, mantidos como importantes para o Brasil desde o início da missão, podem contribuir para o desenvolvimento do país. Dessa forma, o Brasil procurou dar uma demonstração de que se dispunha a exercer um proeminente papel internacional, pelo menos no âmbito do hemisfério, e a vigorar sua disposição de candidato a uma vaga permanente no CSNU (Bandeira 2009; Kenkel 2013; Aguilar 2015). Ademais, o exemplo do Haiti, em que o Brasil comandou o componente militar, mostrou-se como uma possibilidade de aumento de prestígio, de projeção do país no sistema internacional ou a busca da liderança regional, o que pode balizar uma maior ou menor presença em missões sob a égide da ONU (Aguilar 2011; Uziel 2015).

O envio de tropas para a Minustah ensejou uma mudança de paradigma na política externa brasileira. Pela primeira vez, os capacetes azuis do Brasil atuaram sob o Capítulo VII (que permite às Nações Unidas intervir para restabelecer a segurança, a ordem ou a paz em determinada região ou determinado país). De acordo com Braga (2010), a mais recente experiência do Brasil sob a égide da ONU havia sido uma missão do tipo tradicional, sob o Capítulo VI (manutenção da paz), uma década antes, em Angola. Braga (2010) afirma que, para que a missão fosse bem-sucedida, o componente militar identificou a necessidade do emprego da força contra os grupos armados que assolavam o país em um nível maior do que havia sido considerado inicialmente por alguns países contribuintes de tropa. Isso demandou à Minustah adaptações ao contexto haitiano, sobretudo no que diz respeito às regras de engajamento do Capítulo VII. 
A experiência com a OMP no Haiti, que claramente evidenciou o apoio às estruturas e preceitos da Carta das Nações Unidas, representa uma amostragem das propostas e da capacidade como um ator internacional diferente (Valença e Carvalho 2014). O país somente aceitou enviar tropas para a ilha caribenha após a devida autorização pelo CSNU de uma missão robusta, por meio de um mandato que alternou elementos do Capítulo VI com elementos do Capítulo VII (Diniz 2005; Amorim, 2011). A maneira como o Brasil conduziu a sua participação na Minustah é, portanto, um exemplo de legitimidade em fóruns internacionais

Ao mesmo tempo em que evidenciou a abordagem multilateral do Brasil em relação à segurança ao se engajar em uma missão de paz sancionada pela ONU (Christensen 2013), o país demonstrou sua capacidade de se tornar um importante agente regional de segurança, ao mesmo tempo em que reforçou a reivindicação de um assento permanente no CSNU (Valença e Carvalho 2014). Nesse sentido, preocupações com o hard power estiveram por trás da liderança do Brasil na missão da Minustah, que demonstrou a capacidade do país de exercer efetivamente o poder de polícia em âmbito regional e a coerência com a sua política externa. Por outro lado, Valença e Carvalho (2014) destacam que, sob o discurso e a aparência externa do soft power, a Minustah também revelou um lado mais tradicional e de força política do papel do Brasil nas operações de manutenção da paz.

\section{O HARD POWER DO BRASIL NA MINUSTAH}

\section{Expressão econômica}

A utilização de equipamentos fabricados ou montados no Brasil foi um aspecto comum às missões transcorridas em Angola e em Moçambique e aumentou significativamente a partir da Minustah. Na ilha caribenha, a complexidade da Missão exigiu grande capacidade logística das tropas brasileiras, demandando equipamentos e materiais de maior valor tecnológico agregado. Diferentemente das missões anteriores, no Haiti houve uma maior participação de empresas nacionais no fornecimento de produtos ao contingente.

De forma a verificar como ocorreu este processo, realizou-se uma pesquisa quantitativa e qualitativa das empresas que estabeleceram contratos com as FA do Brasil, conforme descrito por Hernandes ${ }^{7}$ (2017). Foram estudadas Empresas Estratégicas de Defesa (EED), assim como outras que estiveram na ilha caribenha, mas que não são enquadradas como Empresas de Defesa (ED) ou EED, com a finalidade de coletar informações acerca 
das empresas brasileiras fornecedoras de equipamentos militares e de emprego geral para o contingente do país desdobrado no Haiti

A pesquisa quantitativa foi realizada entre os dias 14 de junho e 4 de setembro de 2017. A base de dados para a quantificação dos resultados pretendidos consiste em 22 empresas $^{8}$ que receberam a sondagem inicial, das quais 13 repassaram informações para a presente pesquisa.

Foi demandado incialmente para que as empresas respondessem quantos acordos e/ou contratos foram estabelecidos com as FA do Brasil nos últimos 20 anos. Conforme pode ser visto no gráfico 1, cerca de $70 \%$ responderam que firmaram mais de 10 acordos e/ou contratos.

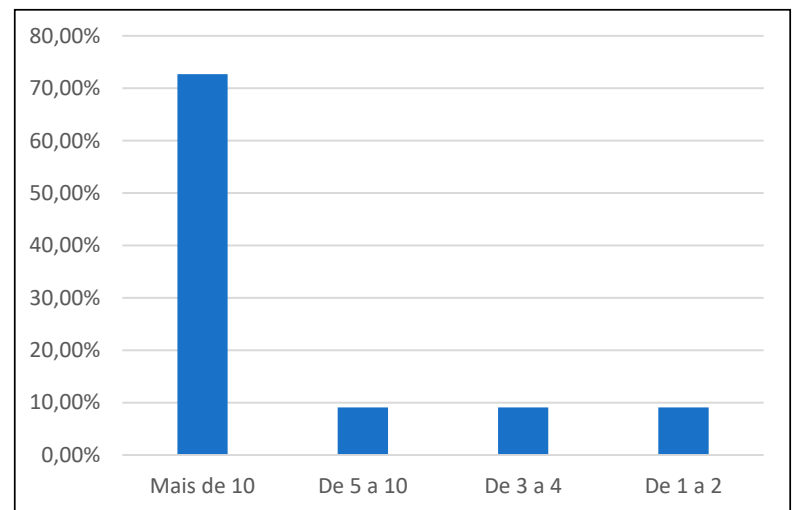

Gráfico 1 - Acordos e/ou contratos estabelecidos com as Forças Armadas nos últimos vinte anos.

Fonte: o autor. Disponível em https://www.onlinepesquisa. $\mathrm{com} / \mathrm{s} / \mathrm{dff} 2220$.

Foram feitos questionamentos acerca dos contratos estabelecidos especificamente para a missão na ilha caribenha (Gráfico 2), tendo-se obtido uma proporção relativamente estreita entre acordos firmados exclusivamente para a missão (65\%) e os que não foram (35\%). 


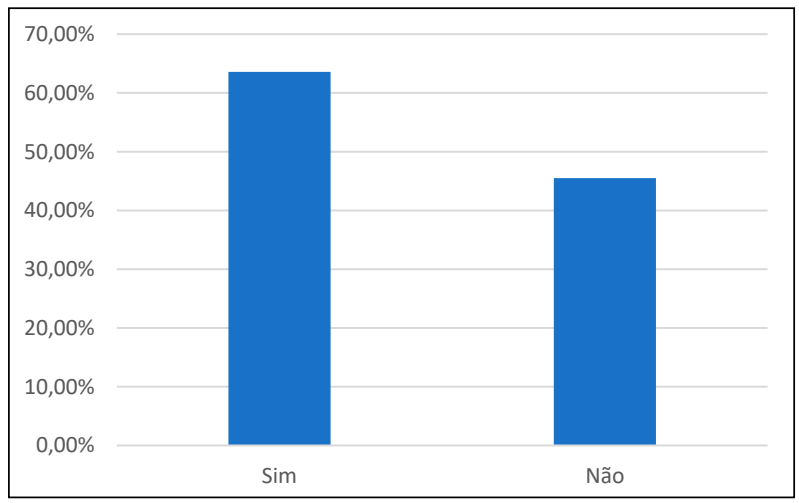

Gráfico 2 - Acordos/contratos firmados com militares brasileiros especificamente para a Minustah.

Fonte: o autor. Disponível em https://www.onlinepesquisa. $\mathrm{com} / \mathrm{s} / \mathrm{dff} 2220$.

Por fim, foi questionado se houve aumento da exposição dos produtos das empresas por meio de suas utilizações pelas FA brasileiras em operações de paz (Gráfico 3).

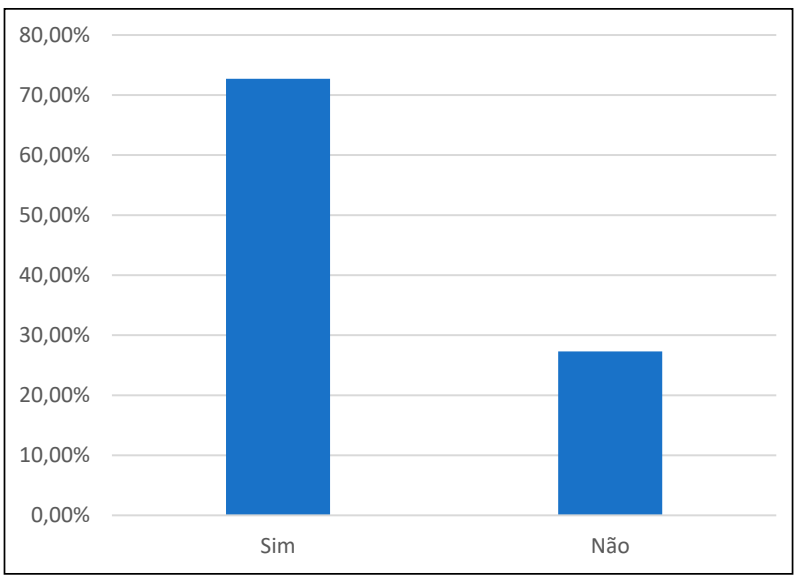

Gráfico 3 - Aumento da exposição de produtos pelo uso em missões de paz.

Fonte: o autor. Disponível em https://www.onlinepesquisa. $\mathrm{com} / \mathrm{s} / \mathrm{dff} 2220$. 
Os resultados obtidos permitem afirmar que cerca de $75 \%$ das empresas firmaram contratos com as FA do Brasil nos últimos anos. Destes contratos, cerca de $65 \%$ foram estabelecidos para atender demandas do contingente militar brasileiro na Minustah. Ademais, a missão representou um aumento de mais de $72 \%$ de visibilidade dos produtos no exterior. Dessa forma, a missão ensejou um aumento na exposição dos produtos de defesa no exterior por meio do universo analisado.

A partir do que foi respondido nos questionários enviados, procedeu-se a uma análise qualitativa, o que envolveu entrevistas com as empresas, cujos resultados mais significativos são apresentados a seguir.

$\mathrm{O}$ fornecimento de tecnologias não letais pela Condor ensejou uma mudança na concepção da ONU sobre o uso da força (Câmara dos Deputados 2013). A empresa passou a fabricar munições não letais mediante solicitação da própria Organização, aumentando de forma expressiva seu mercado (Monteiro 2017), gerando um ciclo virtuoso iniciado por meio da atuação das tropas brasileiras em situações violentas que puderam ser controladas com o auxílio da munição por ela fornecida.

O "veterano" ${ }^{\circ}$ carro de combate Urutu, fabricado pela Engesa, mostrou-se adequado para as operações, mesmo após as agruras sofridas durante a missão (Bastos 2012). Tais vicissitudes demandaram trabalhos de repotencialização e de adaptação (Bastos 2012), realizados pelo Arsenal de Guerra de São Paulo, contando com peças de reposição fabricadas pela Columbus (Neto 2017). Nesse sentido, a logística para um veículo fabricado entre as décadas de 1980 e o começo dos anos de 1990 tornou-se exequível por haver empresas brasileiras em condições de apoiar a realização da manutenção imposta pelas dificuldades da operação em ambiente urbano (com ruas estreitas e maior exposição a disparos).

A fabricação de equipamentos mediante solicitação e atendendo às exigências do EB, por empresas não inscritas como EED, é um legado importante deixado pelo Haiti. Nesse sentido, destaca-se a Perenne, que fabricou uma Estação de Tratamento de Água sob encomenda do Exército Brasileiro (Guanaes 2017), atendendo às especificidades inerentes a um equipamento militar, colocando a Força Terrestre no estado da arte no que concerne ao tratamento de água em operações. A partir da missão na ilha caribenha, a empresa passou a investir em outros países além da América Latina, estendendo os seus negócios para o Oriente Médio (Cutait 2012).

Os veículos empregados pelo contingente são outro exemplo de contribuição para a indústria de defesa. A Agrale passou a ter uma linha específica de veículos militarizados (Matos 2017) e pôde aumentar suas encomendas a partir da missão, tanto para as FA do Brasil quanto para as de outros países (Defensa Nacional y Del Mundo 2014). A partir de 2009, as tro- 
pas da Argentina na Minustah passaram a contar com unidades do Agrale Marruá, modelo AM20 para o transporte de tropas e como ambulâncias. Tais viaturas já vinham sendo utilizadas pelas tropas brasileiras na missão e despertaram o interesse dos militares argentinos (Forças Terrestres 2009).

No que concerne ao armamento utilizado, houve a oportunidade de empregar o novo fuzil IMBEL 5,56 IA2 (DefesaNet 2015; Aversa 2017). Destinado a substituir os fuzis 7,62mm, o armamento reúne condições técnicas que permitem ao EB tornar-se um Exército de $4^{\mathrm{a}}$ Geração (Plavetz 2016; Vicente 2017). Dessa forma, a visibilidade em uma operação de paz é um vetor importante que pode estimular futuras encomendas desse material.

A análise da participação das empresas presentes na missão mostrou-se mais qualitativa do que quantitativa. Embora não tenha havido uma presença mais expressiva do empresariado nacional, pode-se afirmar que a Minustah ensejou uma oportunidade para a indústria de defesa do Brasil. Isso pôde ser observado mediante a concepção de novos equipamentos, mediante projetos estabelecidos com o EB, pelo aumento da demanda a partir da missão e pela visibilidade que o Haiti proporcionou tanto às empresas estratégicas de defesa quanto às que não estão inscritas nesta condição. Por meio da visibilidade que elas tiveram na missão, assim como a oportunidade de comprovar a eficiência em uma situação mais próxima possível de uma guerra, as empresas representaram uma possibilidade para o poderio militar e econômico do Brasil, contribuindo para que aumente o seu poder de influência e de atração.

A decisão do Brasil de integrar a Minustah foi decorrência de um objetivo geral da política externa brasileira, sem ter havido a pretensão de obter ganhos econômicos diretos por meio da missão (Diniz 2005). Isso conferiu às empresas fornecedoras de equipamentos para o contingente brasileiro um certo grau de isenção, na medida em que não houve, por parte do governo brasileiro uma política diretamente voltada para o comércio de componentes de defesa destinados às operações de paz. Nesses termos, as vicissitudes enfrentadas pelos capacetes azuis brasileiros na missão vicejaram uma propaganda para a indústria nacional, tanto para as empresas estratégicas de defesa quanto para empresas que atendem às demandas das FA. Outrossim, a expressão econômica do país na Missão está mais ligada ao poder de atração do que propriamente ao hard power.

\section{Expressão militar}

O Brasil assumiu o comando do componente militar de uma missão robusta, com um efetivo de aproximadamente 10 mil homens e mulheres, incluindo 7.200 militares — dos quais 1900 são brasileiros — e 2.800 
membros de polícia constituída (Hoelscher and Norheim-Martinsenb 2014), assumindo um papel incomum no âmbito da ONU (Christensen 2013). Na Minustah, o país indicou de forma ininterrupta, desde o início da missão, todos os seus Force Commanders (FC). Igualmente, forneceu o maior contingente do componente militar, chegando a cerca de $55 \%$ do efetivo das tropas, em cujas áreas de responsabilidade, na parte urbana de Porto Príncipe, estavam os bairros mais problemáticos, como Cité Soleil e Bel Air, que abrigavam mais de 1,5 milhão de pessoas antes do terremoto (Kenkel 2013).

O Batalhão de Infantaria de Força de Paz (Brabat), Unidade do Exército Brasileiro que contava com um Grupamento Operativo de Fuzileiros Navais da Marinha do Brasil, realizou um importante trabalho na pacificação dos bairros mais violentos da capital haitiana. Em 2004 e 2005, quando as gangues começaram a sequestrar líderes empresariais e políticos, houve um crescente clamor por uma resposta pública (Hoelschera and NorheimMartinsenb 2014, 964). Em 2006, uma onda de sequestros e de assassinatos brutais fez com que o presidente René Préval solicitasse à ONU o emprego da força contra as gangues que assolavam Porto Príncipe (Becker 2011, 144; Harig and Kenkel 2017), concedendo luz verde ao Brabat para intervir militarmente e com força nos redutos das gangues (Hoelschera and Norheim-Martinsenb 2014, 964).

As operações foram concebidas para recuperar o controle territorial e inserir uma presença permanente dentro das áreas controladas pelas gangues, alijando-as dos seus redutos (Hoelschera e Norheim-Martinsenb 2014, 964). De acordo com Becker (2011, 141), a situação enfrentada pelas Nações Unidas no final de 2006 em Porto Príncipe poderia ser comparada com Sadr City ou Fallujah: grupos pequenos e vagamente organizados capazes de enxamear um alvo e se esconder rapidamente entre a população.

Em julho de 2007, a Minustah e as autoridades haitianas recuperaram o controle de todas as seções da capital, e as taxas de crimes violentos caíram (Hoelschera and Norheim-Martinsenb 2014, 964). O sucesso das operações permitiu que a Polícia Nacional Haitiana (PNH) - então totalmente apoiada pela equipe de planejamento militar e político da Minustah - impusesse sua presença em Cité Soleil e monopolizasse o uso da violência na área (Hirst and Nasser 2014). Várias centenas de membros de gangues foram presos, e a Minustah estabeleceu uma presença permanente em notórios bairros como Cité Soleil e Bel Air, que antes eram inacessíveis a autoridades locais e internacionais (Hoelschera and Norheim-Martinsenb 2014, 965)

Do ponto de vista tático, as operações foram um sucesso retumbante para os brasileiros, que fizeram uso de táticas como o estabelecimento de 
pontos fortes dentro de áreas controladas por gangues, uso de operações noturnas para reduzir baixas civis, uso extensivo de inteligência em todas as fases das operações por parte das forças armadas brasileiras em Bel Air, Cité Soleil e Cité Militaire (Hoelschera and Norheim-Martinsenb 2014, 964; Hirst and Nasser 2014). Durante a Operação Blue House, por exemplo, as tropas chegaram a realizar o reforço com sacos de terra das paredes dos pontos fortes recém ocupados em apenas 15 minutos, sem sofrer nenhuma baixa, mesmo com intenso fogo por parte das gangues (Dorn 2009, 814).

Por ocasião do término da Operação Jauru Sudamericano, as gangues evitaram contato direto com as forças da Minustah e fugiram de suas fortalezas quando atacadas. Após três meses de operações, Cité Soleil foi completamente recuperada das gangues sem quaisquer fatalidades e apenas alguns feridos por parte das tropas da ONU. As Nações Unidas, em conjunto com o governo haitiano, conquistaram o controle de todas as seções da capital (Dorn 2009, 817). A PNH que, anteriormente, não queria retornar à Cité Soleil, passara a ter plenas condições de mantê-la, já que que os brasileiros haviam assumido a referida zona (Becker 2011, 144).

Martin-Brulê $(2012$, 238) destaca que, em última análise, a superioridade militar per si não é suficiente para assegurar a vitória em uma operação de paz: a estratégia empregada é fundamental para o sucesso. Sobre esse aspecto, Dorn (2009, 814) ressalta que a ONU conduziu operações com largo emprego de inteligência, bem planejadas e bem executadas, de dezembro de 2006 a março de 2007 , alcançando o efeito desejado, apesar dos reveses iniciais. Ademais, a vantagem numérica, empregando o princípio da Massa, conferiu efeito psicológico dissuasório em favor das tropas. Houve também grande emprego da surpresa e de manobras diversionistas, destinadas a criar confusão entre as gangues que, somadas à maior mobilidade dos capacetes azuis, engendrou a minimização de danos colaterais. $\mathrm{O}$ apoio logístico e de engenharia propiciou à Minustah a possibilidade de realizar reparos rápidos de quaisquer danos físicos que pudessem ocorrer às instalações da população.

Cockayne (2014, 755), considera que os sucessos obtidos pelo componente militar da Minustah podem apontar para a forma de operações robustas no futuro, "no meio do povo". Em uma digressão a partir de "A Utilidade da Força”, do General britânico Sir Rupert Anthony Smith, considera que haverá mais necessidade da coleta e do aproveitamento da inteligência criminal do que o emprego de formações militares em massa, mais importância para encontrar pessoas do que objetos e maior relevância sobre influenciar pessoas do que destruir instalações. 
Keen et al. (2010) ressaltam que em Cité Soleil os soldados brasileiros da Minustah ocuparam a área e a transformaram em um ambiente de normalidade, após seis anos de operações bem-sucedidas. Por meio de ações em força, que se destacaram pela firmeza no cumprimento do mandato em bairros e setores extremamente violentos de Porto Príncipe, a tropa brasileira conquistou prestígio internacional (Aguilar 2012). De acordo com Pinheiro (2011), a neutralização das gangues e a realização de trabalhos em proveito da população contribuiu para a conquista de corações e mentes no âmbito da população haitiana, aumentando a credibilidade da tropa brasileira junto à $\mathrm{ONU}$ e à comunidade internacional. Nieto (2012, 169) salienta que o sucesso da operação em Cité Soleil reforçou a imagem da Minustah e das tropas brasileiras que dela participaram.

Nos momentos de maior tensão e que envolveram grande complexidade de coordenação e de ação de comando em todos os níveis, foi ressaltada a liderança de alguns dos FC brasileiros. Devidamente autorizado pela chefia da missão, o General de Divisão Carlos Alberto dos Santos Cruz - FC entre janeiro de 2007 e abril de 2009 - liderou uma série de ações ofensivas destinadas a pacificar a capital haitiana (Harig and Kenkel 2017). O êxito demonstrado nessas operações conduziu o General, mediante convite da ONU, a exercer a chefia do componente militar da operação de paz na República Democrática do Congo (Abdneur 2015, 53). A indicação de Santos Cruz representou uma experiência única para o Brasil, pois se tratou de uma solicitação pessoal, sem ocorrer negociações diplomáticas entre o Itamaraty e o Secretariado da ONU, como ocorreu nos casos da participação na Minustah e na Unifil (Hirst and Nasser 2014; Hirst, 2015).

Durante o terremoto, o General de Divisão Floriano Peixoto Vieira Neto, que havia sido Chefe da Seção de operações do $1^{\circ}$ Contingente Brasileiro em 2004, foi o responsável por coordenar as operações de ajuda humanitária da Minustah após a catástrofe (Keen et al. 2010). Da mesma forma, o General de Divisão Ajax Porto Pinheiro - último FC da Minustah - por ocasião do abalo sísmico, ainda como Coronel, foi o comandante do Brabat, coordenando missões de segurança e de ajuda humanitária. Os exemplos de liderança destes generais ressaltam o grau de preparação militar das Forças Armadas do Brasil.

De acordo com Kenkel (2013), as FA abordaram as OMP do ponto de vista da maximização dos ganhos institucionais. Consoante com esta interpretação, estes ganhos referem-se à oportunidade para o desdobramento, a longo prazo, em um teatro de operações, proporcionando treinamento semelhante à experiência de combate. Valença e Carvalho (2014) consideram que a presença brasileira no Haiti pode ser entendida 
como um catalisador de mudanças nas capacidades e doutrinas das FA. Ademais, Hirst e Nasser (2014) ressaltam que o emprego de tropas na ilha caribenha foi uma primeira oportunidade para o país testar e melhorar os conteúdos e métodos do processo de preparo e de emprego das FA. Outrossim, permitiu-se melhorar a preparação, com a criação de um centro de treinamento e de capacitação para o emprego em OMP, por meio do Centro Conjunto de Operações de Paz do Brasil (CCOPAB), criado em 2005 (Valença and Carvalho 2014), o que propicia a oportunidade de exercer liderança na formação em manutenção da paz em nível regional (Kenkel 2013).

Nieto $(2012,168)$ ressalta que a atuação em OMP provê uma oportunidade de testar equipamentos e técnicas de combate, obter experiência em campanha e ter acesso às capacidades de outras nações que tenham desdobrado tropas ou apoiado a missão. Igualmente, os curtos ciclos de desdobramentos dos contingentes no sistema da ONU permitem que militares com maiores experiências e habilidades adquiridos nas missões possam disseminar o conhecimento em suas Organizações.

\section{A COMBINAÇÃO DE HARD E SOFT POWER PELO CONTINGENTE MILITAR BRASILEIRO NA MINUSTAH}

A disponibilidade da força militar, contudo, não foi o elemento mais importante do esforço do país no Haiti. Ao lado do envio do maior contingente para a Minustah, assim como a indicação de todos os FC, o Brasil esteve engajado em tentativa muito bem-sucedida e orientada para desenvolver uma forma especificamente brasileira, sulista, de construção da paz, como contraproposta ao modelo liberal democrático do Norte que prevalece na abordagem da ONU (Kenkel 2011).

A partir do início da missão, os desafios concentraram-se em dissuadir e desmantelar as gangues locais, sustentando um ambiente estabilizado que permitisse a recuperação do Estado de Direito e melhorando gradualmente as condições econômicas e sociais (Hirst and Nasser 2014). Usando os pontos fortes como base para realizar projetos de conquista de corações e mentes e coletar informações, as forças brasileiras conseguiram acalmar a situação e conquistar a confiança da população local, de tal forma que, como um oficial brasileiro dissera, "Eles estavam entregando os gangsters para nós” (Hoelschera and Norheim-Martinsenb 2014, 964).

As operações militares foram acompanhadas pela implementação de Projetos de Impacto Rápido (QIPs) para reparar os danos causados pela Minustah e ganhar a confiança da população (Hoelscher and NorheimMartinsenb 2014, 964). De acordo com Dorn (2009, 819) e Nieto (2012), 
as tropas da ONU especialmente o contingente brasileiro, foram rápidos em reparar os danos causados às comunidades durante as operações de combate. Os QIP ajudaram a fornecer as necessidades básicas para os moradores locais em um momento em que eles precisavam de assistência rápida e de segurança

Kenkel (2013) salienta que as FA brasileiras - em particular o Exército - foram encarregadas de diversas missões em território nacional, como a provisão de infraestrutura, a entrega de medicamentos durante as ações cívico-sociais e as operações de garantia da lei e da ordem, as quais exigem altos níveis de contato com a população. O Exército Brasileiro, antes de ser empregado na missão, já estava acostumado a lidar com missões no Brasil que guardavam similaridade com o Haiti, estabelecendo um alto nível de contato do pessoal do contingente brasileiro com a população (Kenkel 2010).

Antes das operações para a retomada de Cité Soleil, centenas de panfletos foram lançados a partir de um pequeno veículo aéreo não-tripulado (UAV) para informar a população de que a ONU não visava a prejudicar civis inocentes e que as operações da Minustah ONU tinham o único objetivo de derrotar as gangues (Dorn 2009, 815). Já durante os confrontos com as gangues, após várias horas de intensos combates, o Comitê Internacional da Cruz Vermelha (CICV) solicitou um cessar-fogo temporário para permitir a prestação de ajuda humanitária, incluindo o resgate de civis feridos. O Comandante da Força, General Santos Cruz, concordou rapidamente com o pedido, e um corredor seguro foi estabelecido (Dorn 2009, 816). A intenção do comandante era de conquistar os objetivos evitando ao máximo a possibilidade de danos colaterais (Dorn 2009, 816).

Em 2006, os capacetes azuis brasileiros tomaram uma decisão consciente de remover seus óculos de sol, olhar nos olhos das pessoas e, em contraste com as unidades jordanianas, sair de seus veículos blindados e andar nas ruas e conversar com a população (Call and Abdenur 2017; Greenburg 2013). Além disso, as forças brasileiras anunciaram sua entrada na comunidade alguns dias antes, deixando os líderes de gangues saírem e concedendo às tropas brasileiras a entrada sem que houvesse confronto e a presença contínua nessas comunidades (Call and Abdenur 2017).

Segundo Hirst e Nasser (2014), a proteção da população civil tinha de ser equilibrada com os objetivos políticos e as preocupações humanitárias da missão, e as ordens dadas pelo comandante da força a seus subordinados deveriam garantir que os métodos usados protegessem os direitos humanos da população civil afetada. Nesse sentido, Hirst e Nasser (2014) e Stuenkel e Tourinho (2014), salientam que as questões centrais nesse contexto foram: $\imath$ ) os limites do uso da força em contextos urbanos; ii) o uso dos militares em atividades de controle de multidões; e iii) os métodos 
empregados para neutralizar a presença de gangues violentas, em que a responsabilidade deveria estar acompanhada da eficácia.

O Brasil também acompanhou essas operações com programas sociais. Inúmeros analistas avaliaram e documentaram a reação mais positiva dos habitantes dessas comunidades às unidades brasileiras em relação às tropas anteriores (Call and Abdenur 2017). Projetos realizados pela organização não-governamental brasileira (ONG) Viva Rio proporcionaram apoio importante para a presença militar do Brasil no Haiti. A maioria dessas iniciativas prioriza o engajamento dos jovens locais e sua reinserção em suas comunidades com o objetivo de evitar sua subordinação a um sistema penal fracassado (Hirst and Nasser 2014).

As Unidades brasileiras presentes na missão, o Brabat e a Companhia de Engenharia de Força de Paz (Braengcoy) cumpriram suas atribuições na defesa do mandato da Minustah e, ao mesmo tempo, prestaram relevante apoio à reconstrução do Haiti, ajuda humanitária e socorro a desastres (Silva 2014; Aguilar 2015).

No que concerne à reconstrução, a Braengcoy realizou obras em benefício da população haitiana, particularmente a perfuração de poços artesianos, serviços de terraplanagem, recuperação de estradas e asfaltamento de ruas, assim como o tratamento de água para fornecer à população (Teixeira and Silva 2007), exercendo um papel crucial em proveito da infraestrutura do país (Harig and Kenkel 2017). A relevância do apoio prestado pôde ser atestada ao término da missão com um balanço de mais de $365 \mathrm{mil} \mathrm{m}^{3}$ de produção e transporte de água tratada, 64 poços artesianos perfurados, cerca de $349 \mathrm{mil} \mathrm{m}^{2}$ de asfaltamento de vias e de $815 \mathrm{mil} \mathrm{m}^{2}$ de estradas reparadas, além de $23 \mathrm{mil} \mathrm{m}^{3}$ de escombro/entulho removidos (Departamento de Engenharia e Construção 2017). A Companhia realizou o enquadramento de mão-de-obra civil para executar parte destes trabalhos, o que foi um fator importante para a estabilização do País, objetivo principal da Minustah.

De acordo com Call e Abdenur (2017), em muitas dessas iniciativas, as tropas da Engenharia realizaram trabalhos de construção orientadas para o desenvolvimento, da mesma forma como realizam internamente, por exemplo, em áreas remotas da Amazônia e regiões fronteiriças. O raciocínio é que, contribuindo para a infraestrutura básica, o Brasil pôde não apenas ajudar na reconstrução pós-desastre, mas também impulsionar o desenvolvimento e ajudar a mitigar alguns dos fatores que levam à instabilidade recorrente.

Após o terremoto, diante das dramáticas necessidades de reconstrução do Haiti, o Exército Brasileiro expandiu sua presença militar, especialmente de engenheiros militares, para atender às necessidades de infraestrutura do país (Hirst 2015, 10). A importância dada a esse envolvimento social 
reflete-se no efetivo de Engenharia do Brasil (o maior da Minustah) e em todas as atividades voltadas para a reconstrução do Haiti em que atuou (Valença e Carvalho, 2014).

Ainda sobre ajuda humanitária, as missões executadas pelo Brabat foram muito importantes para a manutenção de um ambiente estável após o terremoto de 2010. O Batalhão provia a segurança da área de missão e escolta de comboios, para que os gêneros oriundos de doações internacionais pudessem ser distribuídos em locais previamente reconhecidos (Silva 2014). Como parâmetro de comparação, em média 80 toneladas de alimentos eram distribuídas durante 5 ou 6 horas, em dois locais da capital, por dia. No primeiro semestre de 2009 toda a Minustah distribuiu cerca de 40 toneladas de gêneros no Haiti (Pinheiro 2011; Cerqueira 2014).

A atuação da tropa do Brasil em ações de reconstrução e de ajuda humanitária insere-se na chamada "cultura brasileira de missões de paz" (Aguilar 2012). Aspectos inerentes ao povo brasileiro, como o caráter negociador, a flexibilidade diante de situações adversas e de perigo, a facilidade de comunicação em ambiente multinacional, assim como a solidariedade, a generosidade e o carinho com os habitantes locais criaram condições para que o contigente brasileiro tivesse uma grande legitimidade na missão. Tais elementos, que podem ser definidos como aspectos do Smart Power da política externa do Brasil, contribuíram para o sucesso da missão, fazendo com que outros países procurem aprender com o "jeito brasileiro de manter a paz" (Aguilar 2012).

No que concerne ao uso da força para cumprir o mandato, o contingente brasileiro evidenciou uma forte determinação para cumprir a sua missão, aliada à capacidade de encontrar soluções para os problemas que se apresentam (Kenkel 2010; Aguilar 2012). Esses preceitos permitiram que a tropa brasileira pacificasse dois bairros muito violentos no Haiti, Bel Air e Cité Militaire, e exercesse o controle da área mais difícil em termos de segurança, Cité Soleil. Apesar da ordem de agir com firmeza contra as gangues, o respeito às tradições e crendices do povo, o aprendizado e o uso de palavras básicas da língua créole faziam parte da orientação aos militares (Aguilar 2012). Outrossim, as ações em força realizadas para a pacificação do país ressaltam a eficiência do emprego da expressão militar por parte do Brasil, ao mesmo tempo em que houve respeito às idiossincrasias sociais e culturais do Haiti.

Relacionada a essa afinidade cultural estava a decisão inicial do Brasil de empregar suas forças com maior contato e proximidade com as populações locais, especialmente em comunidades de favelas como Bel Air e Cité Soleil, que foram consideradas tomadas por gangues criminosas politizadas que se opunham ao governo (Call and Abdenur 2017). O objetivo das Forças Armadas brasileiras era forjar um método apropriado para abordar a realidade haitiana sem se afastar das regras de engajamento da ONU. 
Durante os primeiros anos da Minustah, o foco esteve no uso cauteloso, mas decisivo do Capítulo VII, equilibrado com esforços para estabelecer um ambiente estável para a população local (Hirst and Nasser 2014).

A concepção e implementação da abordagem de ponto forte em áreas de favelas tornou-se o recurso mais poderoso. Consoante com Hirst e Nasser (2014), isso foi combinado com uma série de esforços para criar uma imagem positiva para as forças armadas entre a população haitiana (através de atividades como pavimentação de estradas, assistência médica, atividades culturais e esportivas). Para evitar uma imagem de intervenção militar externa, as tropas brasileiras abriram linhas diretas de comunicação com a população local para garantir que "a mão amiga agisse em conexão com o braço forte” (Hirst and Nasser 2014; Hirst 2015).

As ações dos capacetes azuis brasileiros promoveram uma profícua combinação entre o Hard e Soft Power. Sobre esse aspecto, Kenkel (2010) salienta que os haitianos fugiam com medo das tropas do exército norte-americano durante o período em que estiveram no país (1994-2004), enquanto que as patrulhas a pé realizadas pelas tropas brasileiras eram recebidas com gracejos e de braços abertos.

De forma a quantificar a receptividade às tropas brasileiras, apresenta-se uma pesquisa realizada junto à população haitiana, entre os anos de 2008 a 2017. Conforme se pode perceber no Gráfico 4, a aceitabilidade das tropas brasileiras, que mantinha uma posição de relativo equilíbrio entre favorável e neutra (53\% contra $44 \%$ ) permaneceu em torno de $74 \%$ a partir de 2010.

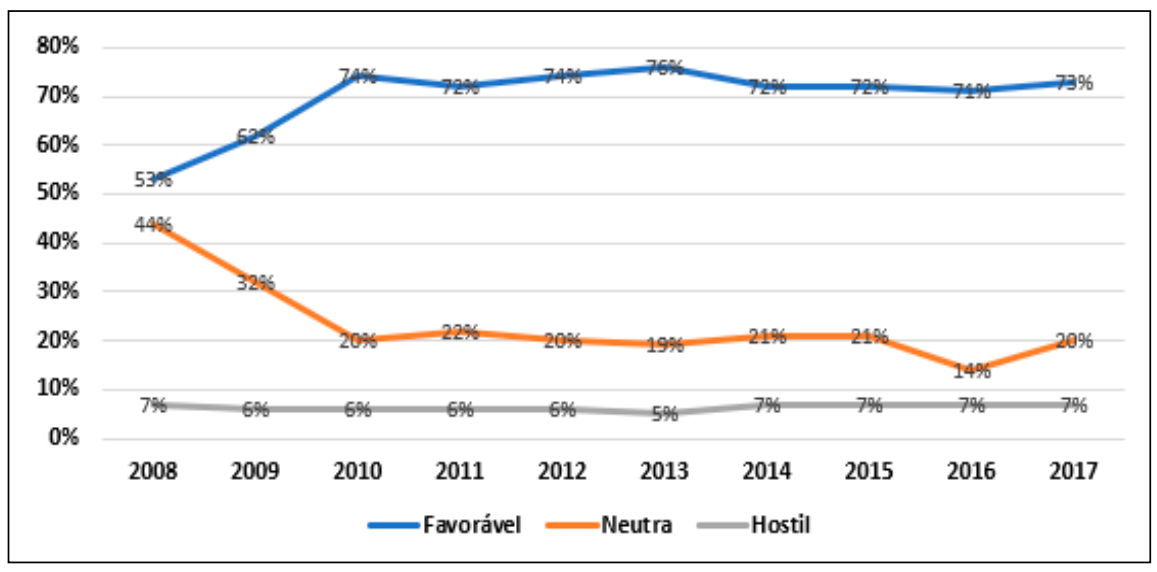

Gráfico 4 - Opinião da população haitiana em relação às tropas brasileiras de paz.

Fonte: Brasil (2017). Elaboração: o autor. 
A grande aceitabilidade aos capacetes brasileiros, contudo, não foi estendida às demais unidades presentes na Missão, conforme pode ser verificado pelo Gráfico 5 .

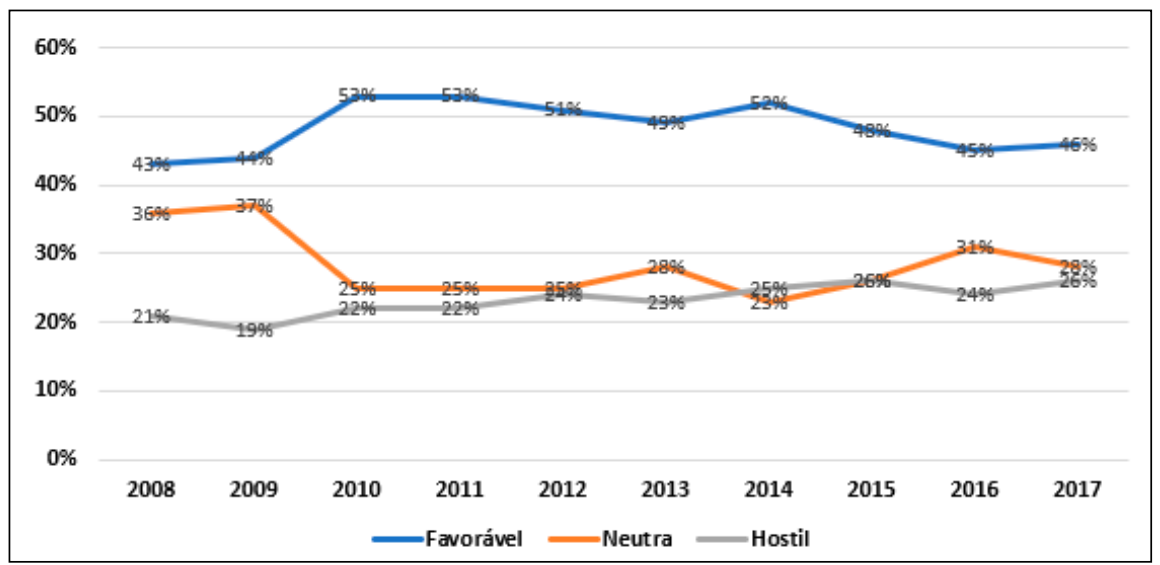

Gráfico 5 - Opinião da população haitiana em relação à Minustah.

Fonte: Brasil (2017). Elaboração: o autor.

A comparação entre os gráficos é um indicador de que houve uma maior receptividade e estima por parte da população haitiana em relação ao trabalho realizado pelo Brasil. A diferença de mais de $20 \%$ de aceitabilidade em comparação com os demais países contribuintes de tropa pode ser creditada às ações bem-sucedidas na pacificação de Cité Soleil, Bel Air e Cité Militaire e durante as catástrofes naturais que assolaram o Haiti. Destarte, a atuação dos capacetes azuis brasileiros converteu-se em poder de atração por meio do emprego da expressão militar do seu Hard Power.

\section{CONCLUSÃO}

A participação do Brasil na Minustah pode ser entendida como um exemplo da tradição grotiana presente na política externa brasileira, na medida em que se alternam elementos realistas e idealistas. Percebem-se elementos do realismo por meio da chefia do componente militar da missão e da cessão do maior efetivo de tropas, voltados para a intenção de ocupar uma vaga permanente no Conselho de Segurança da ONU e para exercer uma maior assertividade em sua política externa. 
Por outro lado, aspectos atinentes ao idealismo, o qual talvez possa ser também considerado uma forma de altruísmo, foram manifestados na solidariedade do contingente brasileiro ao povo haitiano. Isso ficou patente mediante as missões de ajuda humanitária e os trabalhos de reconstrução realizados pelo Brabat e pela Braengcoy. Ademais, o Brasil foi o maior doador para o fundo que foi criado pelo Banco Mundial, tendo fornecido a principal doação pós-terremoto (Amorim 2011).

As operações bem-sucedidas de pacificação do país, como elemento de Hard Power, atestam a importância do poder militar do Brasil, em uma acepção segundo Carr. Igualmente, Morgenthau, ao abordar o grau de preparação militar como um dos seus elementos do poder nacional, ressalta a quantidade e a qualidade das FA. Sobre esse aspecto, o maior efetivo de tropas da Minustah, assim como o protagonismo nas ocasiões em que mais se exigiu o emprego da expressão militar na missão, constituem-se em um elemento de projeção de poder para o Brasil.

Conforme foi apresentado no presente trabalho, pode-se inferir que houve, por meio do contingente brasileiro, uma combinação do Hard e do Soft Power. O poder duro foi manifestado mediante o uso da força militar e da expressão econômica, ainda que não tão notória quanto a das tropas, por meio da participação de empresas brasileiras na missão. Outrossim, o Soft Power foi presenciado nas operações de ajuda humanitária ao Haiti após as catástrofes naturais, assim como nos trabalhos de reconstrução do Haiti e no apoio financeiro do Brasil. Dessa forma, a participação do Brasil na Minustah, contando sempre com os elementos da "cultura brasileira de missões de paz", viceja um arranjo inteligente do poder duro e do poder brando, tornando o “jeito brasileiro de manter a paz” uma manifestação de Smart Power.

Em suma, o Brazilian Way of Peacekeeping alterna momentos idealistas e realistas na participação do Brasil em OMP, notadamente manifestados na Minustah. Destarte, este trabalho tentou prover um estudo de caso que abre novas perspectivas a respeito do potencial que o Smart Power evidenciado pelo contingente brasileiro nessa missão pode representar para a política externa brasileira.

\section{REFERÊNCIAS}

Abdenur, A. E. 2015. "Brazil as a rising power: Coexistence through universalism”. In C. D. Coning, T. Mandrup, and L. Odgaard, The BRICS and Coexistence: An alternative vision of world order, 49-74. Abingdon \& New York: Routledge.

Aguilar, Sergio Luiz Cruz. 2011. "A Participação Sul-Americana nas Operações de Paz da ONU: algumas considerações”. Security and Defense Studies Revierw, v. 12, n. Fall-Winter Issue, p. 99-116, 2011. 
. 2012. "Uma cultura brasileira de missões de paz." In Diplomacia brasileira para a paz, Clóvis Brigagão and Fernanda Fernandes (Org.), 215-241. Brasília: Funag.

2015 . "A Participação do Brasil nas Operações de Paz: passado, presente e futuro." BRASILIANA- Journal for Brazilian Studies 3 no. 2 , 113-141.

Amorim, Celso. 2011. Conversas com jovens diplomatas. São Paulo: Benvirá.

Aversa, Carlos Ernesto Miranda. 2017. (Diretor Fábrica de Material de Comunicações e Eletrônica /Indústria de Material Bélico do Brasil). Entrevista por meio eletrônico em 28 jul. 2017.

Bandeira, Luiz Alberto Moniz. 2009. Geopolítica e política exterior: Estados Unidos, Brasil e América do Sul. Brasília: Fundação Alexandre de Gusmão.

Bastos, Expedito Carlos Stephani. 2012. Blindados no Haiti-Minustah: Uma experiência real. Juiz de Fora: UFJF/Defesa.

Becker, David C. 2011. 'Gangs, Netwar, and 'Community Counterinsurgency' in Haiti." PRISM- National Defense University Press for the Center for Complex Operations, (Junho): 137-154.

Brasil. 1988. Constituição da República Federativa do Brasil de 1988. http://www. planalto.gov.br/ccivil_03/constituicao/constituicaocompilado.htm.

.2012a. Política Nacional de Defesa. https://www.defesa.gov.br/arquivos/ estado_e_defesa/END-PND_Optimized.pdf.

.2012b. Estratégia Nacional de Defesa. https://www.defesa.gov.br/arquivos/estado_e_defesa/END-PND_Optimized.pdf.

.2012c. Livro Branco de Defesa Nacional. https://www.defesa.gov.br/arquivos/estado_e_defesa/livro_branco/livrobranco.pdf.

2014. Ministério da Defesa. Exército Brasileiro. Estado-Maior do Exército. EB20-MC-10.204: Logística. 3. ed. Brasília: EGGCF.

2017. Ministério da Defesa. Exército Brasileiro. Relatório de Emprego do Batalhão de Infantaria de Força de Paz do $26^{\circ}$ Contingente Brasileiro na Missão das Nações Unidas para a Estabilização do Haiti. Brasília (Agosto). 114 p.

Call, Charles T., and Adriana Erthal Abdenur. 2017. "A "Brazilian way"? Brazil's approach to peacebuilding." Latin America Initiative at Brookings (Fevereiro): 1-21. 
Câmara dos Deputados. 2013. "2 1 $1^{\mathrm{a}}$ Reunião da Comissão de Segurança Pública e Combate ao Crime Organizado: Discussão sobre uso de armas não letais para garantir a segurança pública”. http://www.camara.leg.br/internet/sitaqweb/textoHTML.asp? etapa $=11 \&$ nuSessao $=0844 / 13 \&$ nuQuarto $=0 \&$ nuOrador $=0 \&$ nuInsercao $=0 \& d$ tHorarioQuarto $=14 \ldots$.

Carr, E. H. 2001. Vinte Anos de Crise: 1919-1939. São Paulo: Editora Universidade de Brasília, Instituto de Pesquisa de Relações Internacionais.

Cerqueira, Bruno Soares de. 2014 "Coordenação Civil-Militar na Fase de Transição de Operações de Paz Multidimensionais: A Experiência do Brabat 18 no Haiti." Military Review 69 no. 4, 14-27.

Cervo, Amado Luiz, and Clodoaldo Bueno. 2015. História da Política Exterior do Brasil. Brasília: Editora Universidade de Brasília.

Chatin, Mathilde. 2016. "Brazil: analysis of a rising soft power". Journal of Political Power, DOI: 10.1080/2158379X.2016.1232286.

Christensen, Steen Fryba. 2013. "Brazil's Foreign Policy Priorities". Third World Quarterly 34 no. 2, 271-286, DOI: 10.1080/01436597.2013.77578.

Cockayne, James. 2014. "The Futility of Force? Strategic Lessons for Dealing with Unconventional Armed Groups from the UN's War on Haiti's Gangs." Journal of Strategic Studies 37 no. 5 (Junho): 736-769, DOI: 10.1080/01402390.2014.901911.

Cutait, Beatriz. 2012. "Perenne busca sócio para avançar em saneamento". Valor Econômico, 23 abr. 2012. https://www.valoreconomico/20120423/28198607955816.

Defensa Nacional y del Mundo. 2014. "La brasileña Agrale vende 14 vehículos 4x4 Marruá a la infantaria de marina Argentina”. Defensa Nacional y del Mundo 2 dez. 2014.

Defesanet. 2015. "Haiti - Parte o último Contingente da Minustah". Defesanet 13 nov. 2015. http://www.defesanet.com.br/ph/noticia/20827/HAITI---Parteo-ultimo-Contingente-da-Minustah/.

Departamento de Engenharia e Construção. 2017. Informativo Edição Especial Engenharia no Haiti, missão cumprida. Brasília: Exército Brasileiro - Departamento de Engenharia e Construção.

Diniz, Eugenio. 2005. "O Brasil e a Minustah.” Security and Defense Studies Revier, 90-108. 
Dorn, A. Walter. 2009. "Intelligence-led Peacekeeping: The United Nations Stabilization Mission in Haiti (Minustah), 2006-07." Intelligence and National Security, 9 de Dezembro: 805-835. DOI: 10.1080/02684520903320410.

Fontoura, Paulo Roberto Tarisse de Campos da. 2005. O Brasil e a operações de paz das nações unidas. Brasília: Fundação Alexandre de Gusmão.

Forças Terrestres. 2009. "O mercado militar da Agrale". Forças terrestres, 8 mar. 2009. http://www.forte.jor.br/2009/03/08/omercadomilitardaagrale/.

Garcia, Eugênio Vargas. 2004. Cronologia das Relações Internacionais do Brasil. Brasília: Contraponto.

Godofredo Júnior, Gustavo Sénéchal de. 2005. Entre Poder e Direito: A Tradição Grotiana na Política Externa Brasileira. Brasília: Fundação Alexandre de Gusmão.

Greenburg, Jennifer. 2013. “The 'Strong Arm' and the 'Friendly Hand': Military Humanitarianism in Post-earthquake Haiti". Journal of Haitian Studies, Volume 19, Number 1, Spring: 95-122. DOI:10.1353/jhs.2013.0011.

Guanaes, Nelson de Oliveira. 2017 (Presidente da Perenne Equipamentos e Sistemas de Água S/A). Entrevista por meio eletrônico em 15 jun. 2017.

Hamann, Eduarda Passarelli. 2016. "A Força de uma Trajetória: O Brasil e as Operações da ONU (1947-2015)." Military Review 71 no. 4, 47-62.

Harig, Christoph, and Kai Michael Kenkel,. 2017. "Are rising powers consistent or ambiguous foreign policy actors? Brazil, humanitarian intervention and the 'graduation dilemma". International Affairs 93 no. 3, 625-641; DOI: 10.1093/ia/ iix051.

Hernandes, Fernando César. 2017. (Coronel do Exército Brasileiro, Gerente da Subchefia de Operações de Paz da Chefia de Operações Conjuntas do Ministério da Defesa). Entrevista concedida ao autor em 19 abr. 2017.

Hirst, Monica. 2015. "Emerging Brazil: The Challenges of Liberal Peace and Global Governance." Global Society, 2 mar. DOI: 10.1080/13600826.2015.1008422.

Hirst, Monica, and Reginaldo Mattar Nasser. 2014. "Brazil's involvement in peacekeeping operations: the new defence-security foreign policy nexus". Oslo: Norwegian Peacebuilding Resource Centre.

Hoelscher, Kristian, and Per M. Norheim-Martinsenb. 2014. "Urban violence and the militarisation of security: Brazilian 'peacekeeping' in Rio de Janeiro and Portau-Prince." Small Wars \&' Insurgencies, 6 out. 2014: 957-975. 
Keen, P. K., Floriano Peixoto Vieira Neto, W. Nolan, L. Kimmey, and Joseph Althouse. 2010. "Os Relacionamentos são Importantes: Assistência Humanitária e Socorro em Desastre no Haiti”. Military Review 90 no. 4, 17-28.

Kenkel, Kai Michael. 2010. "South America's Emerging Power: Brazil as Peacekeeper". International Peacekeeping 17 no. 5, 644-661, DOI: 10.1080/13533312.2010.516958.

. 2011 "Interesses e identidade na participação do Brasil em Operações de Paz." Revista Tempo do Mundo (IPEA) 3 no. 2 , 10-35.

. 2013 "Brazil". In Providing Peacekeepers: The Politics, Challenges, and Future of United Nations Peacekeeping Contributions Alex J. Bellamy and Paul D. Williams (Org.), 335-354, Oxford: Oxford University Press.

Keohane, Robert O., and Joseph. S. Nye Jr. 2012. Power and Interdependence. Boston: Longman.

Kissinger, Henry. Diplomacy. 1994. New York: Simon \& Schuster Paperbacks.

Krishnasamy, Kabilan. 2007. "Recognition' for Third World peacekeepers: India and Pakistan." International Peacekeeping, 8 nov. 2007, 56-76. DOI:10.1080/13533310108413920.

Krishnasamy, Kabilan, and Auriol Weigold. 2003. "The paradox of India's peacekeeping." Contemporary South Asia, 3 jun. 2010, 263-280. DOI:10.1080/0958493 02000147708 .

Matos, José Alberto da Rosa de. 2017.(Gerente de Vendas de Utilitários da Agrale). Entrevista por meio eletrônico em 31 jul. 2017.

Maquiavel, Nicolau. 2010. O Príncipe. Tradução de Antonio Caruccio Caporale. Porto Alegre: L\&PM.

Martin-Brulê, S.-M. 2012. "Assessing Peace Operations' Mitigated Outcomes". International Peacekeeping (April): 235-250 DOI:10.1080/13533312.2012.665703.

Monteiro, Luiz Cristiano Vallim. 2017. (Diretor de Relações Institucionais da Condor Tecnologias Não-Letais). Entrevista por meio eletrônico em 28 jul. 2017.

Morgenthau, Hans Joachim. 2003. A política entre as nações: a luta pelo poder e pela paz. Brasília: Editora Universidade de Brasília, Instituto de Pesquisa de Relações Internacionais; São Paulo: Imprensa Oficial do Estado de São Paulo. 
Murray, R. W., and J. McCoy, 2010. "From Middle Power to Peacebuilder: The Use of the Canadian Forces in Modern Canadian Foreign Policy". American Review of Canadian Studies 40 no. 2, (25 May), 171-188, DOI: 10.1080/02722011003734712.

Nasser, Filipe. 2012. "Pax Brasiliensis: Projeção de Poder e Solidariedade na Estratégia Diplomática de Participação Brasileira em Operações de Paz da Organização das Nações Unidas”. In O Brasil e as operações de paz em um mundo globalizado : entre a tradição e a inovação, Kai Michael Kenkel, and Rodrigo Fracalossi de Moraes (Orgs.), 213-241. Brasília: Ipea.

Neto, Odilon Lobo de Andrade. 2017 (Diretor da Columbus Comercial Importadora e Exportadora Ltda). Entrevista por meio eletrônico em 10 ago. 2017.

Nieto, W. A. 2012 . "Brazil's Grand Design for Combining Global South Solidarity and National Interests: A Discussion of Peacekeeping Operations in Haiti and Timor". Globalizations, February 9 no. 1, 161-178.

Nye, Joseph S. 2004. Soft Power: The Means to Success in World Politics. New York: Public Affairs. 2011. The Future of Power. New York: Public Affairs.

Pecequilo, Cristina Soreanu. 2014. "O Brasil e a Teoria das Relações Internacionais: balanço e perspectivas.” In Teoria das Relações Internacionais: as questões mundiais em debate, André Luiz Varella Neves (Org.), 423-471. Petrópolis: Vozes.

Pinheiro, Ajax Porto. 2011. "A Atuação do Batalhão Brasileiro Após o Terremoto do Haiti." Military Review 66 no. 1, 31-37.

Plavetz, Ivan. 2016. "Processo de produção do fuzil IA2 da IMBEL". Tecnodefesa (26 jan. 2016). http://tecnodefesa.com.br/processo-de-producao-do-fuzil-ia2-da-imbel/.

Seitenfus, Ricardo. 2006. "Elementos para uma diplomacia solidária: a crise haitiana e os desafios da ordem internacional contemporânea." Carta Internacional 1 no. 1 (março).

Silva, Fabricio Leite. 2014. "Imparcialidade e Independência em Situações de Crise: O Sucesso do Batalhão Brasileiro na Minustah.” Military Review 69 no. 2, 2-11.

Stuenkel, Oliver, and Marcos Tourinho. 2014. "Regulating intervention: Brazil and the responsibility to protect". Conflict, Security \& Development 14 no. 4, 379402, DOI: $10.1080 / 14678802.2014 .930593$ 
Teixeira, Carlos Alberto Maciel, and Gladstone Themóteo M. B. Silva. 2007. "A Participação da Engenharia Militar Brasileira na Missão das Nações Unidas para a Estabilização no Haiti- Minustah.” Military Review 87 no. 3, 32-38.

Uziel, Eduardo. 2015 O Conselho de Segurança, as missões de paz e o Brasil no mecanismo de segurança coletiva das Nações Unidas. Brasília: Fundação Alexandre de Gusmão.

Valença, Marcelo M. and Gustavo Carvalho. 2014 "Soft Power, Hard Aspirations: The Shifting Role of Power in Brazilian Foreign Policy." Brazilian Foreign Policy Journal 8 no. 3, 66-94. DOI:10.1590/1981-38212014000100021.

Vicente, Felipe Ferreira Lima. 2017. "O IA2 como armamento de dotação dos Fuzileiros Blindados no combate de $4^{a}$ geração.” DefesaNet (16 jun.). http://www. defesanet.com.br/doutrina/noticia/26118/O-IA2-como-armamento-de-dotacao-dos-Fuzileiros-Blindados-no-combate-de-4\%C2\%AA-geracao.

Visentini, Paulo Gilberto Fagundes. 2013. "José Honório Rodrigues: historiador do interesse nacional e da africanidade." In Pensamento Diplomático Brasileiro: Formuladores e Agentes da Política Externa (1750-1964) Volume III, José Vicente de Sá Pimentel (Org.), 905-938. Brasília: Fundação Alexandre de Gusmão. 


\section{NOTAS}

1. Os demais elementos do poder nacional são a geografia (extensão territorial, características do relevo) e os recursos naturais (alimentos, matérias-primas) (Morgenthau 2003).

2. A Missão das Nações Unidas em Moçambique (ONUMOZ) estendeu-se até o fim de 1994.

3. III Missão de Verificação das Nações Unidas em Angola (UNAVEM III)

4. De acordo com Maquiavel (2010), a ação do homem virtuoso (Virtù) atualiza e torna efetiva a possibilidade inscrita na situação histórica que a fortuna oferece.

5. Idem.

6. A Raison d'État afirmou que o bem-estar do Estado justificava quaisquer meios que fossem empregados para a sua promoção. $\mathrm{O}$ interesse nacional suplantou a noção medieval de uma moralidade universal (Kissinger 1994).

7. Coronel do Exército Brasileiro. Exerceu as funções de Delegado junto à $\mathrm{ONU}$ no Grupo de Trabalho do Brasil para assuntos do Manual de Equipamento Próprio do Contingente, de Delegado junto à ONU como assessor da Missão Permanente do Brasil nas reuniões da Comissão Especial para Operações de Paz e Chefe da Divisão de Operações Correntes do Comando Logístico do Exército, responsável por coordenar e controlar o apoio logístico às tropas em Operações de Paz.

8. Foi enviada tanto para Empresas Estratégicas de Defesa quanto para empresas que atenderam a demandas das FA, a saber: Agrale, Taurus, Condor Tecnologias não-letais, Imbel, Santoslab Drones, Glágio, Motorola Solutions, Heimer Geradores, Companhia Brasileira de Cartuchos (CBC), SDMO Geradores, Perenne, Zodiac Mardiesel, Deutz Motores a Diesel, Yamaha Motor da Amazônia Ltda., Avibras, MAN Latin América Indústria e Comércio de Veículos Ltda., Iveco, Komatsu, Ford, Mercedes-Benz, Columbus Comercial Importadora e Exportadora Ltda.

9. O veículo blindado de transporte de pessoal EE-11 Urutu foi construído na década de 1980 pela Engesa (Engenheiros Especializados S/A), uma das integrantes do tripé do complexo industrial-militar brasileiro da época. Além do uso intenso pelo Exército, ele foi exportado para países como o Iraque e a Líbia e ainda está operando na Bolívia, Colômbia, Emirados Árabes Unidos, Equador, Gabão, Jordânia, Paraguai, Suriname, Tunísia, Venezuela, Zimbábue e no próprio Brasil (Bastos 2012). 


\section{CAPACETES AZUIS BRASILEIROS NO HAITI:}

INSTRUMENTO DE SMART POWER PARA A POLÍTICA EXTERNA DO BRASIL?

\section{RESUMO}

A atuação do Brasil na Minustah alternou elementos de Hard Power, ressaltado nas operações de pacificação, e de Soft Power, durante a ajuda humanitária e reconstrução. $\mathrm{O}$ artigo pretende analisar se a presença do Brasil no Haiti pode ser entendida como instrumento de Smart Power para a sua política externa.

Palavras-chave: Política Externa Brasileira; Operações de Paz; Smart Power; Contingente Militar Brasileiro.

\section{ABSTRACT}

Brazil's role in Minustah has alternated elements of Hard Power, highlighted in the pacification operations, and Soft Power during humanitarian aid and reconstruction. This paper aims to analyze whether Brazil's mission in Haiti might be understood as a Smart Power instrument for its foreign policy.

Keywords: Brazilian Foreign Policy; Peacekeeping Operations; Smart Power; Brazilian Military Contingent. 